\title{
Swarm-Assisted Investment Planning of a Bioethanol Plant
}

\section{Grzegorz Redlarski ${ }^{1 *}$, Marek Krawczuk ${ }^{1}$, Adam Kupczyk ${ }^{2}$, Janusz Piechocki ${ }^{3}$, Dominik Ambroziak ${ }^{1}$, Aleksander Palkowski ${ }^{1}$}

\author{
${ }^{1}$ Department of Mechatronics and High-Voltage Engineering, Gdansk University of Technology, \\ G. Narutowicza 11/12, 80-233 Gdansk, Poland \\ ${ }^{2}$ Department of Production Management and Engineering, Warsaw University of Life Sciences, \\ Nowoursynowska 164, 02-787 Warsaw, Poland \\ ${ }^{3}$ Department of Electrical Engineering, Power Engineering, Electronics, and Control Engineering, \\ University of Warmia and Mazury, M. Oczapowskiego 11, 10-719 Olsztyn, Poland
}

Received: 7 November 2016

Accepted: 29 December 2016

\begin{abstract}
Bioethanol is a liquid fuel for which a significant increase in the share of energy sources has been observed in the economies of many countries. The most significant factor in popularizing bioethanol is the profitability of investments in construction of facilities producing this energy source, as well as the profitability of its supply chain. With the market filled with a large amount of equipment used in the bioethanol production process, it is often difficult to make an optimal decision regarding the investment. Another issue is the location of the plant itself. Economic benefits are strongly associated with costs of equipment and materials, the amount of revenue from sales, and transportation costs. This article presents an attempt to solve this problem by using several swarm algorithms - new and fast-growing optimisation techniques. By employing ant colony optimization, river formation dynamics, particle swarm optimization, and cuckoo search algorithms in the task of bioethanol plant investment planning, the overall suitability of this type of technique has been tested. Moreover, the results allow us to determine which of the preceding algorithms is the most efficient in the given task.
\end{abstract}

Keywords: bioethanol, combinatorial problem, investment planning, optimization, swarm algorithms

\section{Introduction}

Bioethanol is a liquid fuel obtained from the process of alcoholic fermentation of biomass or biodegradable municipal waste (e.g., paper or wood). Year after year a significant increase in the share of this type of energy

*e-mail: grzegorz.redlarski@pg.gda.pl

source is observed in the economies of many countries. Bioethanol is mainly used in transport as a fuel mixture with gasoline at concentrations of $10 \%, 20 \%$, and $85 \%$ (labelled as E10, E20, and E85, respectively) [1-2]. This solution allows for a significant reduction of greenhouse gases released into the atmosphere during combustion of fuel in car engines [3].

Bioethanol is divided into three types based on the material used for its production [4-5]: 
- First generation: sugar beets, wheat, corn, sugar cane, etc.

- Second generation: waste, residues, and lignocellulose biomass

- Third generation: algae and seaweed

Only the first generation of bioethanol is currently produced and used on a large scale [4]. The second generation of bioethanol is being implemented for widespread use in several years, while the third generation is still under development.

Bioethanol has gained in popularity in recent years, especially in European countries. This gain is related to the current policy of the European Union regarding renewable sources of energy, as well as to the ecoefficiency of bioethanol-based fuels [6]. Increased demand for bioethanol and other renewable energy sources is due to several international regulations, which pays increasing attention on the growing share of renewable energy and the environmental impact of technology [7-11].

However, a major factor in popularizing bioethanol is the profitability of investing in the construction of facilities producing this energy source, as well as the profitability of its supply chain. A number of factors affect the price of bioethanol: the current economic and political situation of a country, the size of taxes and subsidies, current demand for biofuels, and production and operating expenses [4, 12]. Therefore, in the initial phases of an investment, the selection of appropriate equipment, technology of production, and the location of the plant itself is crucial [12].

Currently, the market is filled with a large number of producers of equipment used in bioethanol production. The equipment varies not only by price, but also by total capacity, power, and efficiency. The multitude of choices of equipment and a wide range of power, performance, and capacity make the issue of bioethanol production line design non-trivial. During the design, one should first determine the required minimum capacity of devices based on expected annual production of bioethanol. By using devices with high energy efficiencies, a direct reduction in annual emission of harmful substances into the atmosphere is noticed. This is also crucial for annual expenditure on energy consumption. In addition, taking into account a limited budget, the role of the designer of a production line is highly responsible, and any errors are associated with prolonged payback time.

The literature mostly presents examples of bioethanol or biogas production optimisation. Most of the works concentrate on optimising variables associated with chemical processes that occur during bioethanol or biogas production. There are diverse examples of finding an optimal operating point that satisfies various constraints, determining an optimal control strategy, or finding a constant substrate mixture - all of which lead to optimal and stable operation of the plant. Examples of such work follow. Optimising an anaerobic sequencing batch reactor with the use of artificial neural networks and genetic algorithms demonstrated a clear improvement in biogas production [13]. Using Particle Swarm Optimization in optimising substrate feed mix resulted in a $20 \%$ improvement in biogas production [14]. Another use of particle swarm optimization for optimising values of certain biogas production process variables (e.g., temperature, $\mathrm{pH}$ value) in a multi-layer perceptron neural network model resulted in a $20.8 \%$ increase in biogas production [15].

Another aspect that should be included in the decision process regarding bioethanol plant investments is plant location. Economic benefits are strongly associated with costs of materials, amount of revenue from sales, and transportation costs. In general, production costs of biofuel are associated with the facility size and location [16]. Therefore, the location of the plant should be optimised to maximise profit. Celli et al. presented a system based on genetic algorithms, which enable optimal biomass power plant distribution [17]. Another example used a mixedinteger linear programming model to optimise supply and delivery of ethanol [18]. Mixed-integer linear programming was also used to optimise the design and planning of biomass-based fuel supply networks according to financial criteria [19]. A mathematical model for optimising cost of a switchgrass-based biofuel supply chain was developed likewise using mixed integer linear programming [20]. Biorefinery location was based on the transportation cost of biomass and biofuel. An example of performance optimisation of a biofuel supply chain was carried out by a two-stage stochastic mixed-integer linear programming model with the sample average approximation algorithm [21]. There are several other examples of mixed-integer linear programming optimisation of biofuel supply chains [22-24], which appears to be the most used method at present.

A limited number of sources present an actual system for biogas or bioethanol plant design assistance. One is a piece of software developed by M. Samer to plan and design biogas plants and their concrete structures [25]. However, despite its capability to specify many details of the plant (such as dimensions of tanks or the amount of construction materials), it is incapable of performing any higher-level optimisation. Optimised results from a mixed integer non-linear programming model were used to incorporate structural enhancements in distillation columns and heat integration inside a bioethanol plant to reduce steam consumption [26]. Problems regarding capacity expansions of production and storage facilities of supply network over time, along with associated planning decisions, were successfully solved using the sample average approximation algorithm [27]. There is also a number of articles that present examples of optimisation of biofuel production processes by selecting appropriate technologies used in a refinery [28].

As is apparent from the foregoing description, some of the work uses natural-inspired algorithms, especially swarm algorithms (particle swarm optimization in particular) to solve relevant problems. Swarm algorithms are a set of stochastic metaheuristics used in various optimisation tasks. An inspiration for their development was the behaviour of social animals and various natural 
phenomena. Their effectiveness in solving complicated, multidimensional problems has been extensively proven, and suggests that this will also be the case for the presented problem. In fact, the effectiveness of swarm algorithms in optimising biofuel plant supply chains has been proven [29].

Almost all of the foregoing examples of literature describe optimisation of biofuel supply chains and their major constituents, such as feedstock availability, harvesting capacity, and site locations, transportation network, storage, or regional economic structure, and policy. A more technical side of bioethanol plant planning seems to be omitted, i.e., selection of particular pieces of equipment that constitute a plant.

This article tries to answer two questions: is it possible to develop a versatile tool for bioethanol investment planning, and whether and what swarm algorithms are effective in solving the presented problem. That is the problem of planning first-generation bioethanol plant construction with minimisation of equipment and operating costs. Therefore, an optimisation system based on selected swarm algorithms has been developed. The following swarm algorithms were tested: ant colony optimization (ACO), river formation dynamics (RFD), particle swarm optimization (PSO), and cuckoo search (CS). The system was developed with its simplicity and flexibility in mind, so that simultaneous optimisation of plant equipment and location could be done by a single algorithm. In this respect, the article presents a new approach to the described problem.

The obtained results allow us to conclude that this type of methodology can find a use in making investment decisions for investors and developers.

\section{Overview of the Bioethanol Plant Model Used}

This article incorporates as its model a first-generation bioethanol plant. The first-generation bioethanol production process consists of a number of different minor processes such as washing, cutting, extracting, carbonation, alcoholic fermentation, and distillation. Fig. 1 presents in detail the process of bioethanol production from sugar beet to the final product: bioethanol $[10,30]$. The model presented is a simplified one that considers only the main production process. Whether the addition of more factors (e.g., power or water processing) would significantly affect the model remains an open question.

The sugar beet production process stands as follows. Transported in autumn and before further treatment, sugar beets first must be washed thoroughly. Barrel washers clean the beets and separate them from stones, sand, and weeds. Then sugar beets are cut into what is called slice. Slice is flooded with suitably prepared warm water to extract sucrose from the beets. As a result of extraction, a raw juice containing $13-14.5 \%$ sugar is obtained. In order to purify the raw juice from pollutants, lime milk

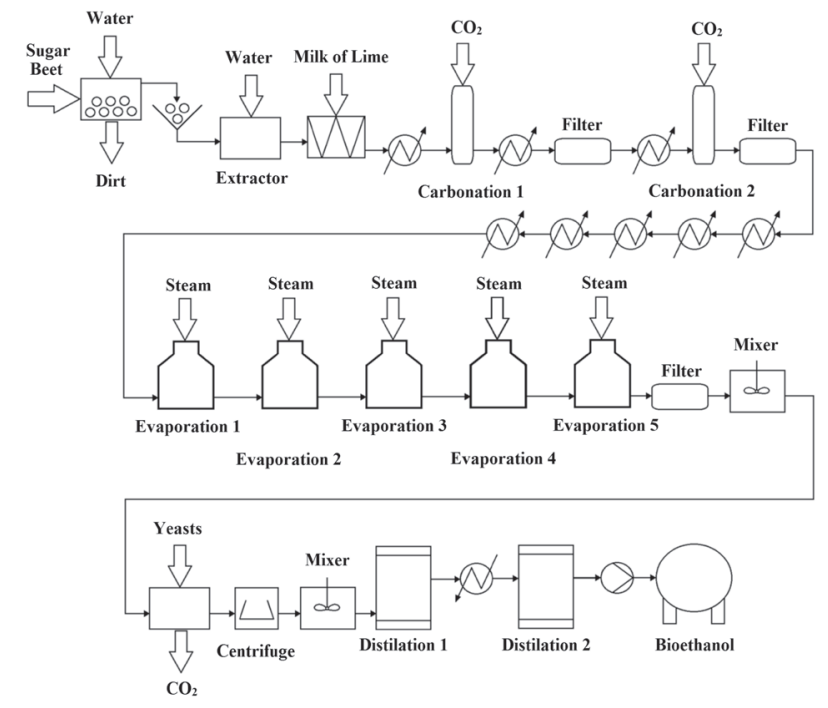

Fig. 1. Considered bioethanol production process.

is added and then the mixture undergoes the process of carbonation. After filtering off impurities from the raw juice, a thin juice is obtained (approximately 15\% sugar content). The next step in the production of bioethanol is thickening the thin juice to increase its sugar content. Thin juice is repeatedly passed through evaporators. At the end of the evaporation process a thick juice, containing $68-71 \%$ sugar, is obtained. Then, using yeast in the fermentation process, carbon dioxide and ethanol is produced $(5-7 \%$ concentration of pure ethanol). The final stage of the production of bioethanol is its distillation to increase the concentration of pure alcohol in the finished product. Distillation is repeated two or three times (95-96\% ethyl alcohol concentration).

As is apparent from the foregoing description, the complexity of the production process of bioethanol enforces the use of a large amount of specialized equipment, such as: barrel washers, cutting machines, carbonators, filters, centrifuges, mixing tanks, evaporators, and distillers. All mentioned equipment, in addition to its costs, has characteristics that highly affect the production process and its efficiency (such as capacity or energy efficiency). Depending on the expected results, the selection of particular pieces of equipment is not an easy task.

\section{Methods}

\section{Problem Formulation}

The problem presented in the introduction requires the selection of successive elements of the technological process of bioethanol production. As shown in Fig. 1, the production process can be separated into different stages in which particular pieces of equipment sequentially process the beet juice. For each stage, a list of potential instruments and their characteristics (price, power, efficiency) can be created. Furthermore, the plant must be 
placed in a suitable location, on which all raw material and transportation costs are dependent (after selecting appropriate buyers and sellers).

Therefore, a combinatorial problem with one objective function can be formulated. The objective function is to minimise expenditures calculated on the basis of initial plant equipment costs, as well as operation costs and sum of revenue throughout the first year. The presented problem can be written in the following form:

$$
\begin{cases}\min F(e q, s, b, l) & \\ \text { subject to: } & h(e q, s, b) \geq p_{a}, \\ & e q \in L_{p}\end{cases}
$$

...where $F(e q, s, b, l)$ is the objective function being the total costs $C$ incurred by the first year (2) dependent on chosen equipment $e q$, plant location $l$, sugar beet sellers $s$, and bioethanol buyers $b$. The limitation $h(e q, s, b)$ is the annual production of bioethanol, which should be greater or equal to intended minimum production $p_{a}$. Additionally, all chosen equipment must form a complete bioethanol production line $L_{p}$, comprised of $p$ production stages (as in Fig. 1).

$$
C=C_{E}+C_{E N}+C_{S B p}-R_{B E}+C_{S B}+C_{B E}
$$

The total costs are dependent, among other things, on purchase costs for equipment (3) and energy expenses (4) - all of which depend on characteristics of particular chosen pieces of equipment.

$$
\begin{gathered}
C_{E}=\sum_{i} c^{i} \cdot k^{i}, \quad i=1,2, \ldots, p \\
C_{E N}=Q_{e l} \cdot G
\end{gathered}
$$

...where:

$$
Q_{e l}=100 \cdot t_{W} \cdot \sum_{i \epsilon e q} P^{i} \cdot \eta_{e l}^{i} \cdot n^{i}
$$

Therefore, to support the given equations, a list of equipment for each type used in the production process (i.e., barrel washers, cutting machines, carbonators, filters, centrifuges, mixing tanks, evaporators, and distillers) has been established (Appendix a). Their price, efficiency, and capacity were loosely based on existing equipment, and assigned randomly for purposes of the tests. These characteristics stand for the basis for determining the value of objective functions. During the investment simulation it is crucial to not only choose a particular machine, but to choose their number as well - as it dictates whether overall device capacity fits the expected annual production.

In addition, the plant is designed to provide a certain amount of bioethanol per year. This imposes the use of constraints to filter out incorrect solutions. This is used mainly to verify whether all tanks provide adequate capacity, and whether all beet sellers can provide the appropriate amount of raw material.
The second part of the presented issue is plant location optimisation. In contrast to a more sophisticated plant location model developed by Zhang et al. [20], a simple model for the purpose of location optimisation has been prepared. Fig. 2 presents a map of potential locations for the bioethanol plant. In addition to the free fields for the plant, the map includes locations of eight sugar beet suppliers (marked grey) and 10 buyers of fuel (marked black). The choice of a particular field is dictated by the cost of purchase (6) and transportation (8) of sugar beets, and selling (7) and transport (9) costs of bioethanol. All sugar beet providers and fuel stations have been assigned with appropriate purchase prices, randomly distributed to simulate diverse yet levelled economic circumstances (Appendix b). Sugar beets are purchased once a year from chosen sources, whereas bioethanol is sold on a monthly basis. Truck tonnage capacity and tank litre capacity were assumed as constant and equal to, accordingly, $12 \mathrm{t}$ and 28,300 1. Transportation costs are dependent on the distance between a buyer/seller and the plant, which was assumed as a Cartesian distance between particular fields with constant transportation cost per unit (\$20 US in this case). All sellers and buyers have their minimum and maximum supply and demand, which provides information as to whether they are suitable for the given case.

$$
\begin{gathered}
C_{S B p}=\sum_{i} c_{S B}^{i} \cdot m_{S B}^{i}, \quad i \in\langle 1,8\rangle \\
R_{B E}=\sum_{1}^{12} \sum_{i} c_{B E}^{i} \cdot m_{B E}^{i}, \quad i \in\langle 1,10\rangle \\
C_{S B}=\left[40 \cdot \sum_{i} m_{S B}^{i} / 12 \cdot l_{S B}^{i}\right], \quad i \in\langle 1,8\rangle \\
C_{B E}=\left[40 \cdot \sum_{1}^{12} \sum_{i} m_{B E}^{i} / 28300 \cdot l_{B E}^{i}\right], \quad i \in\langle 1,10\rangle
\end{gathered}
$$

It is apparent that the presented issue is a combination of a simplified supply chain design with additional production optimisation variables. Like scheduling, the described problem focuses on deciding how to commit available resources between a variety of possible tasks. In this manner each of the listed equipment must be assigned to proper production stages. Each of the listed sugar beet suppliers and buyers of fuel must be assigned as well. All selected variables must be subject to the limitations concerning appropriate production volume and composition of the bioethanol production line. The limitations are mostly verifiable at the very end of the selection process. Due to complexity in verifying the relevant tasks, the raised problem can be considered as NP-hard. In fact, a complex scheduling or supply chain problem is often considered as NP-hard and dealt with the use of modern heuristic optimisation methods [31].

A problem $H$ is NP-hard (non-deterministic polynomial-time hard) when every problem $L$ in NP can be reduced in polynomial time to $H$. If a solution for $H$ takes one unit time, it can be used to solve $L$ in polynomial time. 
The presented optimisation problem can be solved twofold. It can be modelled as a routing problem in a polytree, i.e., a directed decision tree (Fig. 3). Nodes of this graph represent particular devices and locations of the bioethanol plant. Edges of the graph represent total cost transitions. The solution in this case would be a path from an initial node to final node, where all subsequent nodes on the path represent particular pieces of equipment, plant locations, and buyer/seller locations to be chosen.

The second possibility is to conduct a search for the optimum point in a multidimensional space, based on an objective function. Each of the variables determine the choice of a particular device for the appropriate stage of production, and choice of locations on the map for beet suppliers and bioethanol buyers, which adds up to 37 optimisation variables to be determined. Both approaches have been tested to determine the most suitable.

$$
s_{i}=\left\{e q_{1}, e q_{2}, \ldots, e q_{35}, l o c_{S B}, l o c_{B E}\right\}
$$

... where $e q_{n}$ indicates a chosen piece of equipment for a particular production stage, $l o c_{S B}$ indicates the location of a raw material seller from the map, and $l o c_{B E}$ indicates the location of a bioethanol buyer on the map. All variables in this case are integer numbers indicating numbers of particular items from the list or the map.

\section{Ant Colony Optimization}

ACO [32] is one of the first optimisation techniques inspired by the intelligence of animal swarms. The source of inspiration was the behaviour of ant colonies, especially the mechanism of their communication. The ACO algorithm is mainly used in graph problems where it has proven to be highly efficient.

The ant system algorithm is one of the basic algorithms derived from the ACO techniques group. The algorithm by which the optimisation process is carried out is as follows:

1. Assign $m$ agents to the start node.

2. Assign a certain initial amount of pheromone to each edge of the graph.

3. Construct a path for each agent.

4. Update the amount of pheromone on each edge.

5. If $T$ iterations were performed, end the processing; otherwise go to Step 3.

6. Save the best path.

As a well-known algorithm, ACO has found many uses in complicated optimisation tasks. There are numerous examples of job sequencing and operation machine allocation done by the ACO algorithm as well [33].

\section{River Formation Dynamics}

One of the latest methods in the field of swarm intelligence is the river formation dynamics algorithm [34]. The principle of its operation is to imitate the process of riverbed formation. A set of drops, placed at a starting point, is subjected to gravitational force that attracts them to the centre of the earth. As a result, these drops are distributed throughout their environment, seeking the lowest point - the sea.

RFD utilizes this idea into graph theory problems, creating a set of agents that move on the edges between nodes, and explore the environment for the best solution. This is accomplished by the mechanisms of erosion and soil sedimentation. The amount of soil relates to an altitude assigned to each node. Transition from one node to another is carried out according to the decreasing gradient between the nodes. This provides many benefits for the optimisation process (e.g., avoidance of local cycles). In this sense, RFD is a gradient-oriented variant of the ACO algorithm.

The RFD algorithm is as follows:

1. Initialise nodes

2. Initialise drops

3. Move drops

4. Erode paths

5. Deposit sediment

6. Analyse paths

7. If an end condition has been met, end processing; otherwise go to Step 3

Drops move individually until they reach a goal or evaporate - not being able to make a move. The probability that drop $k$ located in node $i$ selects another node $j$ is the following:

$$
P_{k}(i, j)=\left\{\begin{array}{cl}
\frac{\operatorname{gradient}(i, j)}{\sum_{l \in N_{k}(i)} \operatorname{gradient}(i, l)} & \text { if } j \in N_{k}(i) \\
0 & \text { if } j \notin N_{k}(i)(11)
\end{array}\right.
$$

... where:

$$
\operatorname{gradient}(i, j)=\frac{\operatorname{altitude}(i)-\operatorname{altitude}(j)}{\operatorname{distance}(i, j)}
$$

$N_{k}(i)$ represents a set of neighbouring nodes connected to edges of the node in which drop $k$ is located; altitude $(i)$ indicates the amount of soil in node $i$, and distance $(i, j)$ represents edge length between nodes $i$ and $j$.

All nodes are eroded according to Equation (13). The erosion is inversely proportional to the total length of the route of a drop pathLength ${ }_{k}$.

$$
\operatorname{erosion}(i, j)=\frac{\operatorname{gradient}(i, j)}{(N-1) \cdot \operatorname{pathLength}_{k}}
$$

The final step is to deposit a small amount of sediment to all nodes in order to avoid approaching a zero altitude, which would adversely affect the operation of the algorithm. This amount decreases with successive iterations of the algorithm.

\section{Particle Swarm Optimization}

PSO [35] is another example of a stochastic optimisation method. Since its development in 1995 it has gained wide popularity among researchers due to its robustness and effectiveness in solving various optimisation tasks. 


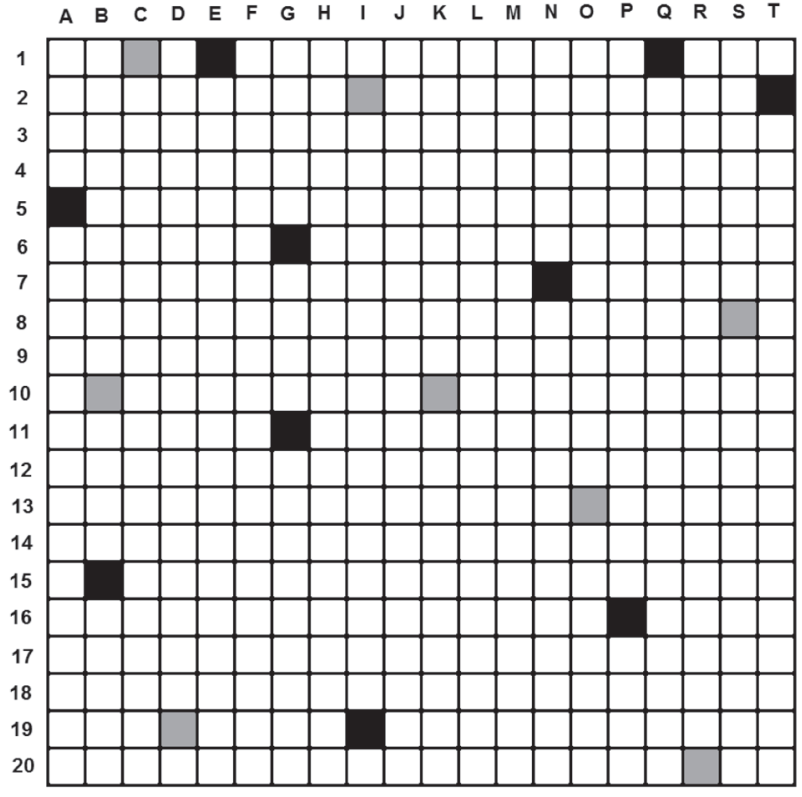

Fig. 2. Map of available locations for the plant. Grey colour marks suppliers of sugar beet and black - petrol stations.

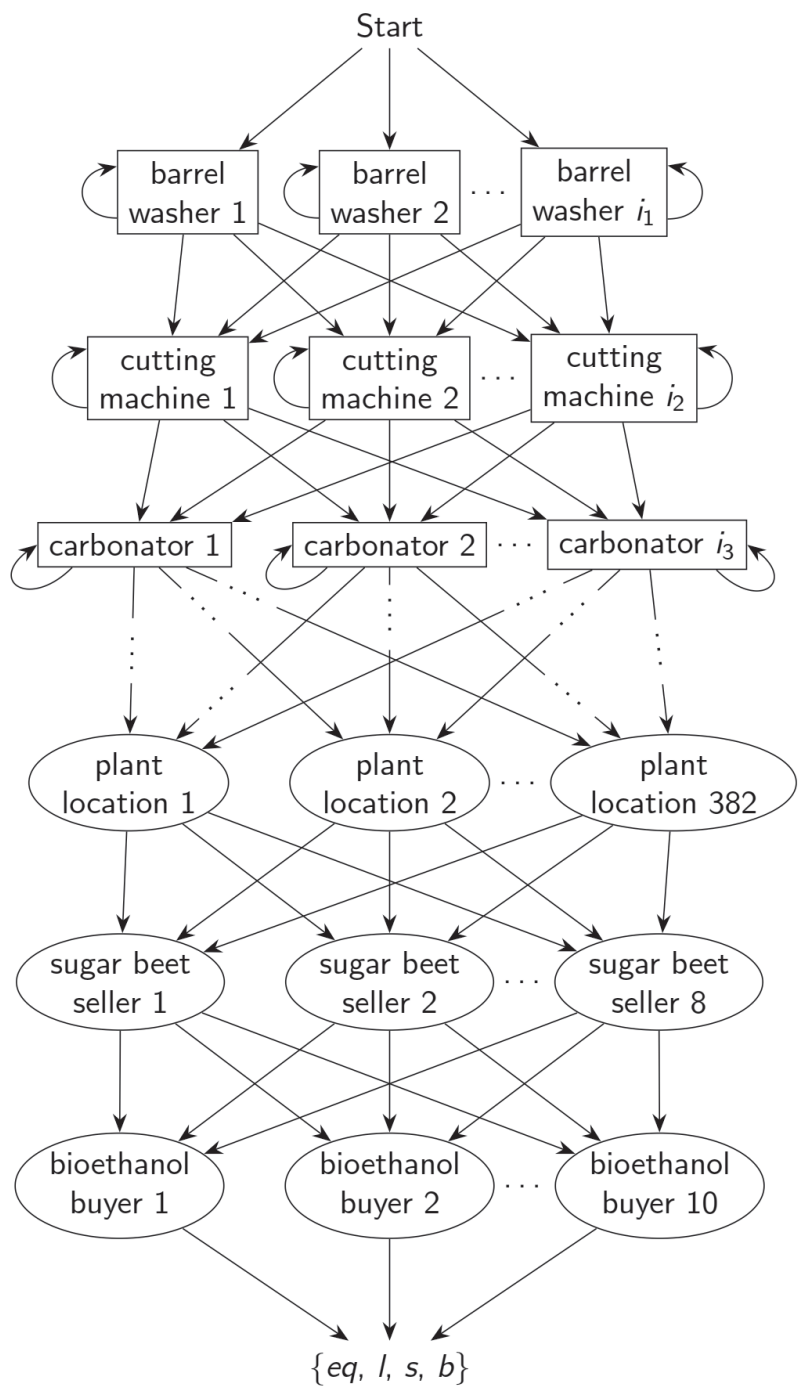

Fig. 3. Simplified decision tree for the optimisation process.
In PSO a number of simple agent-particles is placed in a search space, and each evaluates the objective function at its current location. Each particle $i$ in the swarm is composed of three vectors indicating its current location , previous best location, and velocity . The location of the particle is indicated by a set of coordinates being the problem solution. The PSO algorithm is as follows:

1. Randomly generate initial swarm.

2. Evaluate the fitness of the next particle.

3. Compare particle fitness value with its best; if the current value is better than the best one, then set its best to the current value and set the best location to the current location .

4. Identify the best particle in the neighbourhood and assign its index to the variable $g$.

5. Update the velocity and position of the particle.

6. If all particles have been processed, continue; otherwise go to Step 2.

7. If an end condition has been met, end processing; otherwise go to Step 2.

The PSO algorithm also finds many uses in production optimisation, e.g., in biogas production [36].

\section{Cuckoo Search}

One of the newest swarm algorithms is the cuckoo search, developed by Yang and Deb [37]. It was inspired by the brood parasitism phenomenon seen in some species of cuckoos, which is manifested by placing their eggs in nests of birds of other species. The algorithm applies the mechanism of Lévy flights to select subsequent nests, allowing for proper balance between exploration and exploitation of a search space. A Lévy flight is a random walk in which the steps are defined in terms of the steplengths, which have a certain heavy-tailed probability distribution, with the directions of the steps being isotropic and random.

Each cuckoo lays one or more eggs (in a randomly chosen nest), each representing coordinates of a point in the search space, being the problem solution. The number of nests is fixed, and at the end of each iteration a part of them is rejected with some probability with only the best nests (with the best fitness value) moved to the next iteration. Those assumptions are represented by the following algorithm:

1. Randomly generate initial population of $n$ nests $x_{i}$.

2. Get a cuckoo randomly by Lévy flights and evaluate its fitness.

3. Randomly choose a nest $j$.

4. If fitness of the chosen cuckoo is better than nest $j$, replace $j$ by the new solution.

Table 1. Parametres used in simulation.

\begin{tabular}{|c|c|}
\hline Algorithm iterations & 100 \\
\hline Average annual operating time & 250 days \\
\hline Average motor load of a device & 5.5 \\
\hline Price for $1 \mathrm{kWh}$ of energy & $0.1 \mathrm{USD}$ \\
\hline
\end{tabular}


Table 2. Optimisation results of the considered algorithms for $100000 \mathrm{l} / \mathrm{a}$ bioethanol production.

\begin{tabular}{|c|c|c|c|c|}
\hline & CS & RFD & PSO & ACO \\
\hline Equipment price [USD] & 101005 & 101005 & 101045 & 101005 \\
\hline Energy costs [USD] & 175375 & 175375 & 175375 & 175375 \\
\hline Transportation costs [USD] & 22000 & 12240 & 21040 & 16160 \\
\hline Sugar beet costs [USD] & 688843.80 & 688843.80 & 747887.50 & 688843.80 \\
\hline Revenue [USD] & 61421.58 & 61421.58 & 53004.24 & 61421.58 \\
\hline Total costs [USD] & 925802.22 & 916042.22 & 992343.26 & 919962.22 \\
\hline
\end{tabular}

5. Abandon a fraction of the worst nests and create new ones.

6. Keep the best solutions.

7. If an end condition has been met, end processing; otherwise go to Step 3.

The CS algorithm has proven to be very efficient in solving various engineering optimisation tasks [38]. Furthermore, a modified version of the CS algorithm was previously used in selecting energy system parameters for buildings [39].

\section{Results and Discussion}

The following tests were created to test the capabilities of swarm algorithms in a given task. An optimisation model has been prepared for each of the four swarm algorithms: ant colony optimization, river formation dynamics, particle swarm optimization, and cuckoo search. As mentioned earlier, the problem can be divided into two types based on the used algorithm. Therefore, the ACO and RFD algorithms were used to solve a decision tree problem, and the PSO and CS algorithms conducted a multidimensional space search.

The tests were conducted on a PC with an Intel i7 procesor. Matlab software was chosen as the testing environment. All algorithms were set to work for exactly 100 iterations.

A list of equipment (Appendix a) characterised by price, capacity, power, and energy efficiency was created for all of the production stages, i.e., washing, cutting, extracting, liming, two stages of carbonation, five stages of evaporation, two stages of mixing, fermentation, centrifuging, and two stages of distillation. Moreover, a list of possible sugar beet providers and petrol station locations (Appendix b) with relevant characteristics was

Table 3. Optimisation results of the considered algorithms for 500000 1/a bioethanol production.

\begin{tabular}{|c|c|c|c|c|}
\hline & CS & RFD & PSO & ACO \\
\hline Equipment price [USD] & 133810.00 & 125505.00 & 126650.00 & 136105.00 \\
\hline Energy costs [USD] & 18040.40 & 175798.60 & 184699.80 & 180404.40 \\
\hline Transportation costs [USD] & 23440.00 & 42080.00 & 60720.00 & 31865.00 \\
\hline Sugar beet costs [USD] & 3740252.00 & 3442460.00 & 3442460.00 & 3639172.00 \\
\hline Revenue [USD] & 320835.90 & 320835.90 & 307085.80 & 320835.90 \\
\hline Total costs [USD] & 3594706.50 & 3465007.70 & 3507444.00 & 3666710.50 \\
\hline
\end{tabular}

Table 4. Optimisation results of the considered algorithms for $1000000 \mathrm{l} / \mathrm{a}$ bioethanol production.

\begin{tabular}{|c|c|c|c|c|}
\hline & CS & RFD & PSO & ACO \\
\hline Equipment price [USD] & 217290.00 & 191491.00 & 241845.00 & 191491.00 \\
\hline Energy costs [USD] & 215451.20 & 209647.60 & 209647.60 & 214066.80 \\
\hline Transportation costs [USD] & 198680.00 & 82640.00 & 44920.00 & 43480.00 \\
\hline Sugar beet costs [USD] & 7277724.00 & 6884334.00 & 6884334.00 & 6884334.00 \\
\hline Revenue [USD] & 641671.80 & 641671.80 & 641671.80 & 530004.20 \\
\hline Total costs [USD] & 7267473.40 & 6726440.80 & 6739074.80 & 6803367.60 \\
\hline
\end{tabular}




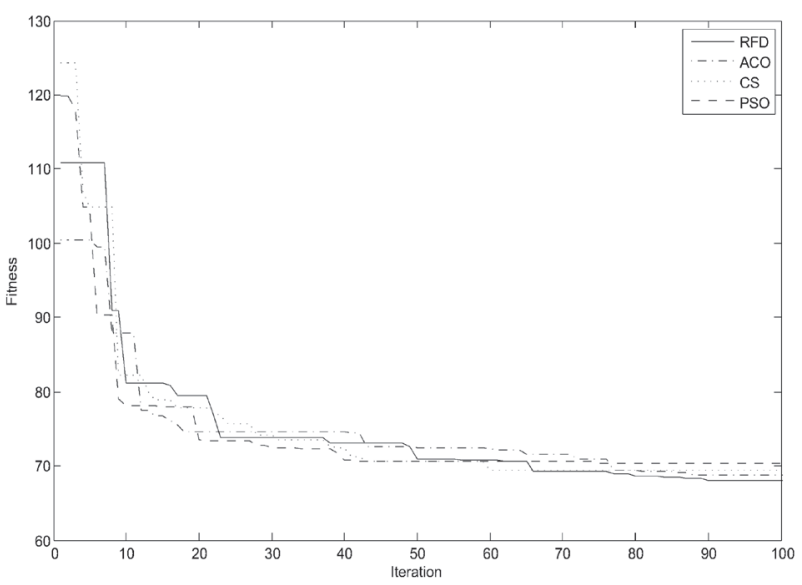

Fig. 4. Normalised fitness function convergence throughout the optimisation process for all considered algorithms.

created. All other factors used in the simulations are presented in Table 1.

The values chosen are not representative of a real bioethanol plant. The model presented is more a proof of successful use of an optimisation system for the said task rather than an example of a proper plant model. In this case, complexity and type of data are more important than the values themselves.

Several tests have been conducted for different expected annual bioethanol production - 100,000 1/a, $500,0001 / \mathrm{a}$, and 1000,000 1/a - for which the results are presented below in Tables 2, 3, and 4, respectively.

As shown in Table 2, the lowest costs were achieved by the RFD algorithm, whereas the highest were obtained by the PSO algorithm. However, overall differences between particular solutions is very little, and equals in the extreme case $\$ 76,301.04$ US. The small difference between all given total costs components is a result of the limited possibility to choose from sugar beet sellers and bioethanol buyers, as well as a clear idea of the amount of equipment to buy. The small annual bioethanol demand influences the necessity for low device capacity and sparse transportation.

Tables 3 and 4 present more diverse results, as the annual bioethanol demand is much higher, which in turn opens more possibilities. In these cases the RFD algorithm achieved the best results as well. There is a much higher difference between equipment costs, because the number of required devices increased with capacity to meet the annual bioethanol demand. In all cases the energy costs are very similar because there is little difference between particular device efficiencies.

The most notable dissimilarity occurs in the case of sugar beet costs. With increased annual demand, the required sugar beet supply increases as well, which makes the choice of particular beet supplier and plant location susceptible to high changes in costs. As heuristic optimisation methods, the presented algorithms are not bound to present only the optimal solutions, therefore a small change on the location map may result in a big change in costs of buying and transporting sugar beets. Agents of the space-searching algorithms, such as the PSO and CS, can in some cases make too large a step and omit the best solution. As is apparent, this is the case, since those two algorithms presented the worst results in most instances.

The RFD and ACO algorithms achieved the best overall results, with the RFD algorithm being considerably better. This is due to the fact that the RFD algorithm applies the gradient-oriented method of selecting subsequent nodes. It helps to avoid local cycles, and reinforces the best paths while still possessing the possibility of finding different routes. In the case of the other two algorithms, the CS algorithm surpassed the PSO in accordance with numerous other studies that compared those two algorithms.

This proves that the RFD and ACO algorithms are characterised in this case by the best convergence and robustness. To better illustrate this, a convergence comparison has been made. Fig. 4 presents how the four tested algorithms converged throughout the optimisation process. It can be stated that the RFD algorithm achieved the best result in this case. However, it needed more iterations to reach its optimum. All other algorithms converge at a considerably higher rate.

A final conclusion can be drawn from the presented result. That is, the two algorithms that solved the problem as a graph (ACO and RFD) obtained better results than the other two. It follows from this fact that the investment planning problem that was formulated should be considered as a directed graph problem. By this means, the best results can be achieved. Moreover, because of their robustness, swarm algorithms fit into the given problem very well. They can easily adapt to changes in the model, making the investment planning tool very versatile.

\section{Conclusions}

This article presents a comparison of four swarm algorithms - ant colony optimization, river formation dynamics, particle swarm optimization, and cuckoo search - as they relate to the task of first-generation bioethanol plant investment planning. The formulated planning process consists of equipment and plant location choice. With the assistance of those algorithms, additional optimisation for the planning process could be performed.

Two approaches for the given problem have been presented. One of them focuses on solving a polytree problem by sequentially selecting all needed pieces of equipment and the plant location according to cost criteria. The other is formulated as a multidimensional space search, where a sought point indicates indexes of given equipment, their number, and plant, sugar beet seller, and bioethanol buyer locations. The first approach was solved with the ant colony optimization and river formation dynamics algorithms, and the later with the particle swarm optimization and cuckoo search algorithms.

To solve the given problem, a list of equipment with its characteristics (price, power, efficiency, and capacity) was 
Appendix a). Parameters of matched bioethanol plant equipment for each production stage.

\begin{tabular}{|c|c|c|c|c|c|}
\hline Stage & $\begin{array}{l}\text { Price } \\
\text { [USD] }\end{array}$ & $\begin{array}{l}\text { Capa- } \\
\text { city }\end{array}$ & \begin{tabular}{|c|}
$\begin{array}{c}\text { Electrical } \\
\text { efficiency } \\
{[\%]}\end{array}$ \\
\end{tabular} & $\begin{array}{c}\text { Power } \\
{[\mathrm{kW}]}\end{array}$ & $\begin{array}{c}\text { Process } \\
\text { efficiency } \\
{[\%]}\end{array}$ \\
\hline \multirow{5}{*}{ Washing } & 4500 & \multirow{5}{*}{$12 \mathrm{t} / \mathrm{h}$} & 78 & \multirow{5}{*}{2.2} & \multirow{5}{*}{88.2} \\
\hline & 4515 & & 80 & & \\
\hline & 4670 & & 81 & & \\
\hline & 4545 & & 82 & & \\
\hline & 4590 & & 82 & & \\
\hline \multirow{10}{*}{ Cutting } & 2400 & \multirow{5}{*}{$2 \mathrm{t} / \mathrm{h}$} & 74 & \multirow{5}{*}{1.5} & \multirow{10}{*}{$\sim 100.00$} \\
\hline & 3500 & & 82.8 & & \\
\hline & 3545 & & 79 & & \\
\hline & 3615 & & 79 & & \\
\hline & 3570 & & 79 & & \\
\hline & 5673 & \multirow{2}{*}{$3 \mathrm{t} / \mathrm{h}$} & 76 & \multirow{2}{*}{1.5} & \\
\hline & 5783 & & 75 & & \\
\hline & 4500 & \multirow{3}{*}{$3 \mathrm{t} / \mathrm{h}$} & 86 & \multirow{3}{*}{4} & \\
\hline & 4650 & & 85.5 & & \\
\hline & 4560 & & 86 & & \\
\hline \multirow{19}{*}{$\begin{array}{l}\text { Extrac- } \\
\text { tion }\end{array}$} & 1735 & 9001 & \multirow{19}{*}{ 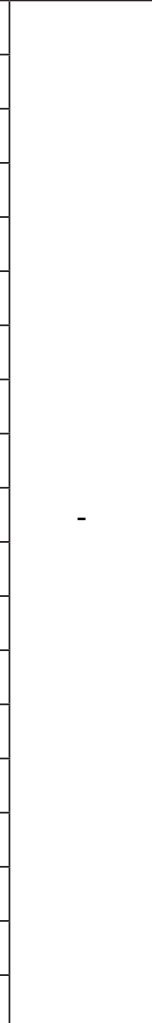 } & \multirow{19}{*}{-} & \multirow{19}{*}{113.73} \\
\hline & 1814 & 11001 & & & \\
\hline & 1848 & 12501 & & & \\
\hline & 2024 & 15501 & & & \\
\hline & 2118 & 19501 & & & \\
\hline & 2387 & 25501 & & & \\
\hline & 2417 & 37501 & & & \\
\hline & 3929 & 56501 & & & \\
\hline & 5396 & 75501 & & & \\
\hline & 5920 & 94501 & & & \\
\hline & 6528 & 113501 & & & \\
\hline & 6969 & 132001 & & & \\
\hline & 9609 & 151001 & & & \\
\hline & 11905 & 189001 & & & \\
\hline & 14225 & 227001 & & & \\
\hline & 17654 & 378501 & & & \\
\hline & 20280 & 454001 & & & \\
\hline & 23327 & 567501 & & & \\
\hline & 27131 & 757001 & & & \\
\hline
\end{tabular}

\begin{tabular}{|c|c|c|c|c|c|}
\hline \multirow{19}{*}{ Liming } & 1735 & 9001 & \multirow{19}{*}{ - } & \multirow{19}{*}{-} & \multirow{19}{*}{106.23} \\
\hline & 1814 & 11001 & & & \\
\hline & 1848 & 12501 & & & \\
\hline & 2024 & 15501 & & & \\
\hline & 2118 & 19501 & & & \\
\hline & 2387 & 25501 & & & \\
\hline & 2417 & 37501 & & & \\
\hline & 3929 & 56501 & & & \\
\hline & 5396 & 75501 & & & \\
\hline & 5920 & 94501 & & & \\
\hline & 6528 & 113501 & & & \\
\hline & 6969 & 132001 & & & \\
\hline & 9609 & 151001 & & & \\
\hline & 11905 & 189001 & & & \\
\hline & 14225 & 227001 & & & \\
\hline & 17654 & 378501 & & & \\
\hline & 20280 & 454001 & & & \\
\hline & 23327 & 567501 & & & \\
\hline & 27131 & 757001 & & & \\
\hline & 11500 & $5500 \mathrm{l} / \mathrm{h}$ & & & \\
\hline & 13800 & $6000 \mathrm{l} / \mathrm{h}$ & & & \\
\hline Carbona- & 16000 & $7000 \mathrm{l} / \mathrm{h}$ & & & 1 \\
\hline tion & 18500 & $8000 \mathrm{l} / \mathrm{h}$ & - & - & 92.19 \\
\hline & 20000 & $9500 \mathrm{l} / \mathrm{h}$ & & & \\
\hline & 24000 & $9800 \mathrm{l} / \mathrm{h}$ & & & \\
\hline & 10000 & 50001 & & & \\
\hline & 35000 & 70001 & & & \\
\hline Evapora- & 45000 & 85001 & & & 7005 \\
\hline tion & 65000 & 100001 & - & - & 18.25 \\
\hline & 80000 & 200001 & & & \\
\hline & 100000 & 500001 & & & \\
\hline & 1700 & & 79 & & \\
\hline & 1710 & 5801 & 79 & 1.5 & \\
\hline & 1740 & & 74 & & \\
\hline & 2500 & & 79 & & \\
\hline & 2375 & & 85.5 & & \\
\hline & 2535 & 1 & 82.5 & 2 & \\
\hline Mixing & 2400 & 22001 & 83 & 3 & $\sim 100.00$ \\
\hline & 2410 & & 84 & & \\
\hline & 2350 & & 84.6 & & \\
\hline & 3500 & & 83 & & \\
\hline & 3300 & 1 & 87.9 & 55 & \\
\hline & 3330 & 28001 & 86 & 5.3 & \\
\hline & 3510 & & 85.5 & & \\
\hline
\end{tabular}


Appendix a). Continued.

\begin{tabular}{|c|c|c|c|c|c|}
\hline \multirow{18}{*}{$\begin{array}{c}\text { Fermen- } \\
\text { tation }\end{array}$} & 1735 & 9001 & \multirow{18}{*}{-} & \multirow{18}{*}{-} & \multirow{18}{*}{148.57} \\
\hline & 1814 & 11001 & & & \\
\hline & 1848 & 12501 & & & \\
\hline & 2024 & 15501 & & & \\
\hline & 2118 & 19501 & & & \\
\hline & 2387 & 25501 & & & \\
\hline & 2417 & 37501 & & & \\
\hline & 3929 & 56501 & & & \\
\hline & 5396 & 75501 & & & \\
\hline & 5920 & 94501 & & & \\
\hline & 6528 & 113501 & & & \\
\hline & 6969 & 132001 & & & \\
\hline & 9609 & 151001 & & & \\
\hline & 11905 & 189001 & & & \\
\hline & 14225 & 227001 & & & \\
\hline & 17654 & 378501 & & & \\
\hline & 20280 & 454001 & & & \\
\hline & 23327 & 567501 & & & \\
\hline \multirow{15}{*}{$\begin{array}{l}\text { Centri- } \\
\text { fugation }\end{array}$} & 2500 & \multirow{4}{*}{$3 \mathrm{t} / \mathrm{h}$} & 82.8 & \multirow{4}{*}{1.5} & \multirow{15}{*}{65.08} \\
\hline & 2545 & & 79 & & \\
\hline & 2600 & & 79 & & \\
\hline & 2575 & & 74 & & \\
\hline & 5000 & \multirow{5}{*}{$12 \mathrm{t} / \mathrm{h}$} & 85.5 & \multirow{5}{*}{4} & \\
\hline & 5180 & & 82.5 & & \\
\hline & 5030 & & 83 & & \\
\hline & 5070 & & 84 & & \\
\hline & 5040 & & 84.6 & & \\
\hline & 10000 & \multirow{3}{*}{$20 \mathrm{t} / \mathrm{h}$} & 87.9 & \multirow{3}{*}{7.5} & \\
\hline & 10145 & & 86 & & \\
\hline & 10350 & & 85.5 & & \\
\hline & 20000 & \multirow{2}{*}{$100 \mathrm{t} / \mathrm{h}$} & 89.4 & \multirow{2}{*}{11} & \\
\hline & 20100 & & 89.8 & & \\
\hline & 30000 & $200 \mathrm{t} / \mathrm{h}$ & 90.6 & 15 & \\
\hline \multirow{8}{*}{$\begin{array}{l}\text { Distilla- } \\
\text { tion }\end{array}$} & 5000 & 6401 & \multirow{8}{*}{-} & \multirow{8}{*}{-} & \multirow{8}{*}{36.5} \\
\hline & 7500 & 12201 & & & \\
\hline & 9500 & 14501 & & & \\
\hline & 9800 & 18001 & & & \\
\hline & 10500 & 200001 & & & \\
\hline & 11500 & 23001 & & & \\
\hline & 13500 & 25001 & & & \\
\hline & 16000 & 32001 & & & \\
\hline
\end{tabular}

prepared, along with a map of possible bioethanol plant locations, sugar beet suppliers, and petrol stations.
Appendix b). Information about sugar beet sellers and bioethanol buyers used in the location map in Fig. 2.

\begin{tabular}{|c|c|c|c|c|}
\hline Type & $\begin{array}{l}\text { Position } \\
\text { on the map }\end{array}$ & $\begin{array}{c}\text { Price } \\
\text { [USD] }\end{array}$ & $\begin{array}{c}\text { Max } \\
\text { amount }\end{array}$ & $\begin{array}{c}\text { Min } \\
\text { amount }\end{array}$ \\
\hline \multirow{8}{*}{ Beet seller } & B10 & $586.25 / \mathrm{t}$ & $12000 \mathrm{t}$ & $2400 \mathrm{t}$ \\
\hline & $\mathrm{C} 1$ & 586.25 & 13000 & 2600 \\
\hline & D19 & 670 & 16000 & 3200 \\
\hline & I2 & 670 & 18000 & 3600 \\
\hline & K10 & 636.5 & 13000 & 2600 \\
\hline & $\mathrm{O} 13$ & 619.75 & 11000 & 2200 \\
\hline & $\mathrm{R} 20$ & 636.5 & 14000 & 2800 \\
\hline & S8 & 619.75 & 12000 & 2400 \\
\hline \multirow{10}{*}{$\begin{array}{c}\text { Bioethanol } \\
\text { buyer }\end{array}$} & A5 & $6.365 / 1$ & 6000001 & 1200001 \\
\hline & B15 & 6.7 & 800000 & 160000 \\
\hline & E1 & 6.365 & 700000 & 140000 \\
\hline & G6 & 7.705 & 1600000 & 320000 \\
\hline & G11 & 7.035 & 1000000 & 200000 \\
\hline & I19 & 7.035 & 1100000 & 220000 \\
\hline & N7 & 7.37 & 1200000 & 240000 \\
\hline & P16 & 6.7 & 900000 & 180000 \\
\hline & Q1 & 7.37 & 1300000 & 260000 \\
\hline & $\mathrm{T} 2$ & 7.705 & 2000000 & 400000 \\
\hline
\end{tabular}

As a result of the tests, we can conclude that the bestperforming algorithm is the river formation dynamics algorithm. Total costs of the investment resulting from its optimisation were slightly lower than those obtained from the ant colony optimization algorithm. Generally, all presented swarm algorithms produced satisfying results and are suitable to solve the bioethanol plant design planning problem.

The polytree approach to the given problem allowed us to obtain better results. The ACO and RFD algorithms have chosen less expensive and more efficient sets of equipment, and more profitable plant locations. This indicates that the given problem should be approached in this way in the future.

Swarm algorithms are characterised by their robustness, and can easily adapt to much more complicated models, which makes the presented tool very versatile. This suggests that adding more detail and subjecting the model to more objective functions and constraints is possible, and can produce satisfying results. Just by the addition of another variable that represents a different characteristic, and its inclusion in an objective function, the model can be easily expanded. The main drawback of the presented test is that the model is based on randomized characteristics of a plant. With more accurate data such a system could be compared with actual bioethanol plants to determine to what extent the optimization can benefit real plant 
developers. Extension to this problem should be a topic for future research.

\section{Nomenclature}

$P^{i} \quad$ Power of $i$-th device [kW]

$R_{B E} \quad$ Revenues from the sale of bioethanol [USD]

$C_{S B} \quad$ Costs associated with transportation of beet [USD]

$C_{B E} \quad$ Costs associated with transportation of bioethanol [USD]

$c_{S B}^{i} \quad$ Purchase price of beet from $i$-th seller [USD $\cdot t^{-1}$ ]

$m_{S B}^{i} \quad$ Amount of beet purchased from $i$-th seller $[\mathrm{t}]$

$c_{B E}^{i} \quad$ Selling price of bioethanol for $i$-th recipient $\left[\mathrm{USD} \cdot 1^{-1}\right.$ ]

$m_{B E}^{i} \quad$ Amount of bioethanol sold to $i$-th recipient [1]

$C_{E} \quad$ Costs associated with the purchase of executive devices [USD]

$c^{i} \quad$ Price of $i$-th device [USD]

$k^{i} \quad$ Number of $i$-th devices [-]

$\eta_{e l}^{i} \quad$ Effciency of $i$-th device [\%]

$l_{S B}^{i} \quad$ Distance to $i$-th seller $[\mathrm{km}]$

$l_{B E}^{i} \quad$ Distance to $i$-th recipient $[\mathrm{km}]$

$t_{W} \quad$ Average annual operating time $[\mathrm{d} / \mathrm{y}]$

$n^{i} \quad$ Average motor load of $i$-th device $[-]$

$Q_{e l} \quad$ Annual electricity consumption $\left[\mathrm{kWh} \cdot \mathrm{y}^{-1}\right]$

$G \quad$ Price for $1 \mathrm{kWh}$ of energy [USD]

$C_{E N} \quad$ Costs associated with the purchase of electricity [USD]

C Total costs [USD]

$C_{S B p} \quad$ Costs associated with the purchase of sugar beet [USD]

\section{References}

1. BAENA L., GOMEZ M., CALDERON J. Aggressiveness of a 20autoparts: I behavior of metallic materials and evaluation of their electrochemical properties. Fuel 95, 320, 2012.

2. PARK S.H., KIM H.J., SUH H.K., LEE C.S. Atomization and spray characteristics of bioethanol and bioethanol blended gasoline fuel injected through a direct injection gasoline injector. International Journal of Heat and Fluid Flow 30, 1183, 2009.

3. NAIK S., GOUD V.V., ROUT P.K., DALAI A.K. Production of first and second generation biofuels: A comprehensive review. Renewable and Sustainable Energy Reviews 14, 578, 2010.

4. SALAZAR-ORDONEZ M., PEREZ-HERNANDEZ P.P., MARTIN-LOZANO J.M. Sugar beet for bioethanol production: An approach based on environmental agricultural outputs. Energy Policy 55. Special section: Long Run Transitions to Sustainable Economic Structures in the European Union and Beyond, 662, 2013.

5. GOH C.S., LEE K.T. A visionary and conceptual macroalgae-based third-generation bioethanol (TGB) biorefinery in Sabah, Malaysia as an underlay for renewable and sustainable development. Renewable and Sustainable Energy Reviews 14, 842, 2010.
6. European Commission. Proposal for a Regulation of the European Parliament and of the Council on Support for Rural Development by the European Agricultural Fund for Rural Development (EAFRD). COM 627, Final/2, 2011.

7. The European parliament and the council of the European Union. Directive 2009/28/EC of the European parliament and of the council of 23 April 2009 on the promotion of the use of energy from renewable sources and amending and subsequently repealing directives 2001/77/EC and 2003/30/ EC. Official journal of the European Union 52, 16, 2009.

8. The European parliament and the council of the European Union. Directive 2009/29/EC of the European parliament and of the council of 23 April 2009 amending directive 2003/87/EC so as to improve and extend the greenhouse gas emission allowance trading scheme of the community. Official journal of the European Union 52, 63, 2009.

9. The European parliament and the council of the European Union. Directive 2009/31/EC of the European parliament and of the council of 23 April 2009 on the geological storage of carbon dioxide and amending council directive 85/337/ EEC. European parliament and council directives 2000/60/ EC, 2001/80/EC, 2004/35/EC, 2006/12/EC, 2008/1/EC and regulation (EC) No 1013/2006. Official journal of the European Union 52, 114-135, 2009.

10. Krajnc, D. \& Glavic, P. Assessment of different strategies for the co-production of bioethanol and beet sugar. Chemical Engineering Research and Design 87. Special Issue on Biorefinery Integration Biorefinery Integration SI, 1217, 2009.

11. REDLARSKI G., PIECHOCKI J., DĄBKOWSKI M. Reducing Air Pollutant Emissions from the Residential Sector by Switching to Alternative Energy Sources in SingleFamily Homes. Polish Journal of Environmental Studies 22, 197, 2013.

12. VUCUROVIC D.G., DODIC S.N., POPOV S.D., DODIC J.M., GRAHOVAC J.A. Process model and economic analysis of ethanol production from sugar beet raw juice as part of the cleaner production concept. Bioresource Technology 104, 367, 2012.

13. FAKHARUDIN A.S., SULAIMAN M.N., SALIHON J., ZAINOL N. Implementing Artificial Neural Networks and Genetic Algorithms to Solve Modeling and Optimisation of Biogas Production in Proceedings of the 4th International Conference on Computing and Informatics, ICOCI 2013, $121,2013$.

14. WOLF C., MCLOONE S., BONGARDS M. Biogas plant optimization using genetic algorithms and particle swarm optimization in IET Irish Signals and Systems Conference (ISSC 2008) (Galway, Ireland), 244, 2008. DOI:10.1049/ cp:20080670.

15. WEI X., KUSIAK A. Optimization of Biogas Production Process in a Wastewater Treatment Plant in Proceedings of the 2012 Industrial and Systems Engineering Research Conference (Orlando, FL), 1, 2012.

16. KOCOLOSKI M., GRIFFIN W.M., MATTHEWS H.S. Impacts of facility size and location decisions on ethanol production cost. Energy Policy 39, 47, 2011.

17. CELli G., GHIANI E., LODDO M., PILO F., PANI S. Optimal location of biogas and biomass generation plants in Universities Power Engineering Conference, 2008. UPEC 2008. 43rd International, 1, 2008. DOI:10.1109/ UPEC.2008.4651490.

18. LEDUC S., STARFELTF., DOTZAUERE., KINDERMANN G., MCCALLUM I., OBERSTEINER M., LUNDGREN J. Optimal location of lignocellulosic ethanol refineries with polygeneration in Sweden. Energy 35, 2709, 2010. 
19. MAS M.D., GIAROLA S., ZAMBONI A., BEZZO F. In 20th European Symposium on Computer Aided Process Engineering (Eds Pierucci S., Ferraris G.B.) 97, Elsevier, 2010. DOI:10.1016/S1570-7946(10)28017-3.

20. ZHANG J., OSMANI A., AWUDU I., GONELA V. An integrated optimization model for switchgrass-based bioethanol supply chain. Applied Energy 102. Special Issue on Advances in sustainable biofuel production and use XIX International Symposium on Alcohol Fuels - ISAF, 1205, 2013

21. OSMANI A., ZHANG J. Economic and environmental optimization of a large scale sustainable dual feedstock lignocellulosic-based bioethanol supply chain in a stochastic environment. Applied Energy 114, 572, 2014.

22. BAI Y., HWANG T., KANG S., OUYANG Y. Biofuel refinery location and supply chain planning under trafc congestion. Transportation Research Part B: Methodological 45, 162. ISSN: 0191-2615, 2011.

23. AKGUL O., SHAH N., PAPAGEORGIOU L.G. Economic optimisation of a UK advanced biofuel supply chain. Biomass and Bioenergy 41, 57. ISSN: 0961-9534, 2012.

24. BALAMAN S.Y., SELIM H. A decision model for cost efective design of biomass based green energy supply chains. Bioresource Technology 191, 97. ISSN: 0960-8524, 2015.

25. SAMER M. A software program for planning and designing biogas plants. Transactions of the ASABE 53, 1277, 2010.

26. KARUPPIAH R., PESCHEL A., GROSSMANN I.E., MARTIN M., MARTINSON W., ZULLO L. Energy optimization for the design of corn-based ethanol plants. AIChE Journal 54, 1499, 2008.

27. KOSTIN A., GUILLEN-GOSALBEZ G., MELE F., BAGAJEWICZ M., JIMENEZ L. Design and planning of infrastructures for bioethanol and sugar production under demand uncertainty. Chemical Engineering Research and Design 90, 359, 2012.

28. TONG K., GONG J., YUE D., YOU F. Stochastic Programming Approach to Optimal Design and Operations of Integrated Hydrocarbon Biofuel and Petroleum Supply Chains. ACS Sustainable Chemistry \& Engineering 2, 49, 2014.
29. CASTILLO-VILLAR K.K. Metaheuristic Algorithms Applied to Bioenergy Supply Chain Problems: Theory, Review, Challenges, and Future. Energies 7, 57. ISSN: 7640-7672, 2014.

30. SANTEK B., GWEHENBERGER G., SANTEK M.I., NARODOSLAWSKY M., HORVAT P. Evaluation of energy demand and the sustainability of different bioethanol production processes from sugar beet. Resources, Conservation and Recycling 54, 872, 2010.

31. YANG X.-S., DEB S., FONG S. In Networked Digital Technologies (Ed Fong, S.) 53-66 (Springer Berlin Heidelberg). ISBN: 978-3-642-22184-2. DOI:10.1007/9783-642-22185-9_6, 2011.

32. DORIGO M., BIRATTARI M., STUTZLE T. Ant colony optimization. Computational Intelligence Magazine, IEEE 1, 28, 2006.

33. PRAKASH A., TIWARI M.K., SHANKAR R. Optimal job sequence determination and operation machine allocation in flexible manufacturing systems: an approach using adaptive hierarchical ant colony algorithm. Journal of Intelligent Manufacturing 19, 161. ISSN: 1572-8145, 2008.

34. RABANALP., RODRIGUEZI., RUBIOF. In Unconventional Computation (eds Akl S., Calude C., Dinneen M., Rozenberg G. \& Wareham, H.) 163-177 (Springer Berlin Heidelberg). DOI:10.1007/978-3-540-73554-0_16, 2007.

35. POLI R., KENNEDY J., BLACKWELL T. Particle swarm optimization. Swarm Intelligence 1, 33, 2007.

36. WEI X., KUSIAK A. Optimization of Biogas Production Process in a Wastewater Treatment Plant in Industrial and Systems Engineering Research Conference, 1, 2012.

37. YANG X.-S., DEB S. Cuckoo Search via Lévy flights in Nature Biologically Inspired Computing, 2009. NaBIC 2009. World Congress on (2009), 210-214. DOI:10.1109/ NABIC.2009.5393690, 2009.

38. YANG X.-S., DEB S. Cuckoo search: recent advances and applications. Neural Computing and Applications 24, 169, 2014.

39. PIECHOCKI J., AMBROZIAK D., PALKOWSKI A., REDLARSKI G. Use of Modified Cuckoo Search algorithm in the design process of integrated power systems for modern and energy self-suffcient farms. Applied Energy 114, 901, 2014. 